\title{
PENGARUH AUTHENTIC LEADERSHIP TERHADAP CUSTOMER-ORIENTED ORGANIZATIONAL CITIZENSHIP BEHAVIOR DAN SERVICE RECOVERY PERFORMANCE MELALUI JOB CRAFTING DAN HR FLEXIBILITY
}

\author{
Aziz Yogatama \\ Universitas Negeri Surabaya \\ aziz.17080574049@mhs.unesa.ac.id \\ Dwiarko Nugrohoseno \\ Universitas Negeri Surabaya \\ dwiarkonugrohoseno@unesa.ac.id
}

\begin{abstract}
This study aims to determine and explain the effect of authentic leadership on service recovery performance and customer-oriented organizational citizenship behavior (Co-OCB) through job crafting and HR flexibility at a telecommunication company, PT. Telkom Indonesia in Surabaya region. This research is causality research with a quantitative approach - the sampling technique used non-probability sampling, namely purposive sampling. Statistical analysis used Partial Least Square (PLS) with SmartPLS 3.0 software. This study explains that authentic leadership does not affect customer-oriented OCB and service recovery performance. Then Co$O C B$ does not have any effect in mediating the relationship between authentic leadership and service recovery performance. However, job crafting has been shown to mediate the relationship between authentic leadership and $\mathrm{Co}-\mathrm{OCB}$ and service recovery performance. HR flexibility is not proven in moderating the relationship between authentic leadership and job crafting in the context of high flexibility.
\end{abstract}

Keywords: authentic leadership; customer-oriented organizational citizenship behavior; HR flexibility; job crafting; service recovery performance.

\section{PENDAHULUAN}

Era globalisasi, persaingan industri bidang teknologi khususnya bidang penyedia layanan jaringan komunikasi sangat ketat. Masing-masing perusahaan memiliki keunggulan kompetitif dengan berbagai macam produk dan layanan yang ditawarkan pelanggan. Agar tetap memertahankan keunggulan kompetitif maka perusahaan diperlukan adanya sumber daya manusia (SDM) yang baik. SDM merupakan hal yang paling penting dalam suatu organisasi karena berperan aktif dalam proses pengambilan keputusan dan bagaimana suatu organisasi tersebut akan berjalan. Perlunya investasi sumber daya manusia menjadikan perusahaan tersebut dapat mecapai keungulan kompetitif, mampu bertahan, dan mampu bersaing. Sesuatu yang akan mengancam kestabilan ekonomi yaitu adanya tenaga kerja yang tidak mampu dalam setiap tantangan yang akan terjadi di sekelilingnya (Sutrisno, 2009). Berdasarkan laporan Asmara (2020), peringkat daya saing Indonesia berada pada posisi 40 dari 63 negara. Peringkat tersebut mengalami penurunan jika dilihat berdasarkan peringkat pada tahun 2019 berada pada posisi 32. Di sisi lain, komponen efisiensi bisnis mengalami penurunan paling drastis dari peringkat 20 tahun 2019 menjadi peringkat 31 pada 2020 (Pranoto, 2020). Rendahnya peringkat kinerja perekonomian akibat dari adanya dampak pandemi Covid-19.

Perusahaan menghadapi pandemi Covid-19 melakukan percepatan digitalisasi. Hal itu dilakukan melihat adanya perubahan perilaku konsumen semenjak adanya pandemi. Dalam melakukan digitalisasi, SDM sebagai kunci utama agar tetap mampu bersaing dengan kompetitor secara efektif serta dapat menunjang pendapatan yang diperoleh perusahaan. Peran pemimpin penjualan sangat penting dalam membantu karyawan dalam menyelesaikan semua tantangan yang dihadapi, khususnya pada karyawan penjualan. Kepemimpinan merupakan salah satu mekanisme dalam membentuk perilaku karyawan penjualan penjualan (Ashill et al., 2008; Babakus et al., 2003).

Pemimpin yang memiliki perilaku authentic leadership dapat memberikan suasana positif yang sesuai dengan kepribadiannya kepada karyawan untuk berkontribusi dan melengkapi sumber daya manusia 
Aziz Yogatama \& Dwiarko Nugrohoseno. Pengaruh Authentic Leadership terhadap CustomerOriented Organizational Citizenship Behavior dan Service Recovery Performance melalui Job Crafting dan HR Flexibility

(Luthans \& Avolio, 2003). Dimitriades (2007) mendefinisikan customer-oriented OCB sebagai serangkaian perilaku individu tertentu yang melampaui peran kerja untuk meningkatkan pelayanan serta kepuasan pelanggan. Babakus et al. (2003) mendefiniskan service recovery performance sebagai kemampuan dan tindakan untuk memerbaiki kegagalan layanan yang diberikan untuk memulihkan kepuasan pelanggan. Penelitian Walumbwa et al. (2008) menunjukkan bahwa authentic leadership berpengaruh signifikan positif terhadap OCB agar karyawan dapat berkontribusi dalam fungsi organisasi di luar apa yang seharusnya dilakukan. Luu (2020) menunjukkan authentic leadership memberikan hubungan signifikan positif terhadap service recovery performance dan customeroriented secara signifikan positif memediasi hubungan antara authentic leadership dengan service recovery performance. Observasi dilakukan pada perusahaan ternyata menunjukkan pemimpin mereka memiliki ciri-ciri perilaku authentic leadership namun dalam implementasinya kurang memberikan dampak secara langsung terhadap perilaku Co-OCB dan service recovery performance karyawan penjualan maupun customer service.

Job crafting sebagai mediasi yang menghubungkan antara authentic leadership, service recovery performance, dan Co-OCB. Tims et al. (2016) menjelaskan bahwa job crafting merupakan suatu perubahan yang dilakukan oleh karyawan itu sendiri terkait pekerjaannya. Joo \& Jo, (2017) menyatakan authentic sales leaders mungkin memengaruhi karyawan penjualan untuk membangun motivasinya secara proaktif dalam pencarian sumber daya sebagai peningkatan diri. HR flexibility dikonseptualisasikan sebagai kemampuan organisasi yang terdiri dari sejauh mana SDM dapat menerapkan berbagai keterampilan dan penampilan perilaku untuk membangun fleksibilias dan responsivitas dalam lingkungan organisasi yang dinamis. Luu (2020) membuktikan HR flexibility memoderasi hubungan authentic leadership terhadap job crafting yang mengacu pada penerapan human resource management (HRM). Liu et al. (2013) menunjukkan kolektivisme HRM memiliki hubungan positif memoderasi peran leadership style dan (Kalshoven \& Boon, 2012) yang menunjukkan efek moderasi pada sistem HRM yang memberikan pengaruh siginifikan negatif pada hubungan ethical leadership terhadap well-being helping.

Tujuan dari penelitian ini adalah untuk mengetahui pengaruh authentic leadership terhadap customeroriented $O C B$ dan service recovery performance melalui job crafting dan HR flexibility.

\section{KAJIAN PUSTAKA DAN PENGEMBANGAN HIPOTESIS}

\section{Authentic Leadership}

Authentic leadership dapat dilihat sebagai pola perilaku pemimpin yang memanfaatkan dan mempromosikan psikologis yang positif dan iklim etika yang positif, untuk menumbuhkan kesadaran diri yang lebih besar, perspektif moral terinternalisasi, dan pemrosesan informasi dan hubungan relasional transparan dari pihak pemimpin yang bekerja dengan pengikut, dan mendorong pengembangan diri positif (Walumbwa et al., 2008). Pemimpin otentik (authentic leaders) memiliki kesadaran dan keterbukaan terhadap kepercayaan pribadi, nilai, motif, dan perasaan pribadi mereka, mendorong dan menyambut masukan orang lain, serta berbagi sumber daya yang diperlukan untuk mengambil keputusan (Wang et al., 2014). Kemudian berperilaku apa adanya, dapat diandalkan, peduli untuk membangun kekuatan karyawan, memperluas pemikiran mereka, dan menciptakan lingkungan kerja yang menarik. Pemimpin otentik juga memanfaatkan sumber daya pribadi positif mereka sendiri untuk berkontribusi dan melengkapi sumber daya bawahan mereka untuk meningkatkan kinerja karyawan (Luthans \& Avolio, 2003). George (2003) mendefinisikan bahwa pemimpin yang otentik memengaruhi anggotanya dengan menyalurkan tanggung jawab yang mendalam untuk memberikan hasil yang positif selama periode yang lama. Ryan \& Deci (2000) dan Kernis (2003) menyatakan karyawan juga dapat berperilaku otentik dengan adanya beberapa faktor yaitu kesadaran dari dalam diri, bentuk internalisasi yang berkaitan dengan regulasi diri sendiri, kemampuan pemimpin dalam mengolah informasi, perilaku authentic leaders, dan transparansi hubungan. Pada tingkat pemimpin individu, adda bukti yang berkembang bahwa pendekatan otentik untuk memimpin adalah sesuatu yang sangat dibutuhkan dan efektif bagi kemajuan SDM di 
perusahaan untuk mencapai hasil yang positif dan bertahan lama dalam organisasi (George et al., 2007).

\section{HR Flexibility}

Bhattacharya et al. (2005) dan Wright \& Snell (1998) mengonseptualisasikan HR flexibility sebagai kemampuan organisasi yang terdiri dari sejauh mana sumber daya manusia memiliki berbagai keterampilan dan penampilan perilaku, lalu sejauh mana praktik SDM secara efektif memanfaatkan sumber daya manusia tersebut untuk membangun fleksiblitas organisasi, responivitas, kelincahan, dan kesuksesan pada lingkungan yang dinamis. HR flexibility dapat merujuk pada perbedaan berbagai lokasi atau unit bisnis, sejauh manakah praktik dasar diterapkan dalam berbagai pekerjaan atau tempat yang berbeda, atau berdasarkan kecepatan manakah yang dapat diubah (Wright \& Snell, 1998). Kemudian memiliki dua dimensi yaitu resource flexibilty dan coordination flexibility (Way et al., 2015). Resource flexibility menunjukkan sejauh mana sumber daya organisasi dapat diterapkan untuk penggunaan yang berbeda dan konteks yang beragam (Sanchez \& Heene, 1997). HR flexibility dapat dirasakan oleh karyawan sebagai sumber daya (Way et al., 2018) di mana mereka dapat memanfaatkannya untuk mengembangkan peran dalam sumber daya mereka dalam melayani pelanggan (Luu, 2016) misalnya seperti job crafting (Luu et al., 2019). Dari pandangan berbasis sumber daya (Wernerfelt, 1984), HR flexibility menghasilkan dan memanfaatkan sumber daya yang tidak ada bandingannya dan tidak tergantikan dalam hal pengetahuan dan dinamisme motivasi di mana memberikan kontribusi kapabilitas yang dinamis terhadap dinamika tim dan organisasi mereka berdasarkan teori kapabilitas dinamis (Teece, 2007).

\section{Job Crafting}

Bakker et al. (2012) mendefinisikan job crafting sebagai perubahan karyawan yang mungkin dilakukan terkait dengan tuntutan pekerjaan dan sumber daya pekerjaan. Sedangkan menurut Wrzesniewski \& Dutton (2001), job crafting menggambarkan perubahan yang dibuat oleh karyawan dalam pekerjaan mereka, termasuk tugas, hubungan, dan kognisi. Karyawan tidak akan menerima secara pasif desain pekerjaan dari organisasi, melainkan mereka akan bertindak proaktif dengan memodifikasi pekerjaan agar sesuai dengan preferensi mereka (Luu, 2020). Dengan job crafting, karyawan akan mengubah batas tugas pekerjaan mereka (jenis atau jumlah kegiatan), batas tugas kognitif pekerjaan (yaitu bagaimana seseorang memandang pekerjaan), dan batas-batas relasional pekerjaan mereka (yaitu dengan siapa orang tersebut berinteraksi di tempat kerja) (Petrou et al., 2012). Ketika karyawan penjualan menyederhanakan pekerjaan pelayanan mereka, mereka dapat memeroleh lebih banyak sumber yang lebih berguna agar dapat berpartisipasi di berbagai aktivitas pekerjaan walaupun melampaui pekerjaan seharusnya (Bavik et al., 2017; Tims et al., 2016). Job crafting ditemukan untuk menjadi satu di antara sumber daya proaktif untuk menambah strategi (Meijerink et al., 2018). Sakuraya et al. (2017) menjelaskan beberapa faktor yang dapat memengaruhi organisasi agar karyawan memiliki tanggung jawab dan wewenang lebih di antaranya seorang manajer tidak lagi merancang pekerjaan untuk karyawan dengan pertimbangan kebutuhan dan keterampilan mereka dan peran penting karyawan adalah merancang pekerjaan atau lingkungan mereka sendiri.

\section{Customer-oriented OCB}

Organ (1988) menjelaskan Organizational Citizenship Behavior (OCB) sebagai perilaku karyawan yang memiliki kebebasan untuk menentukan keputusan sendiri yang melibatkan karyawan untuk berkontribusi pada fungsi organisasi mereka di luar peran kerja dalam suatu deskripsi pekerjaan dan diakui oleh sistem penghargaan formal. Williams \& Anderson (1991) membedakan OCB mejadi dua jenis yaitu Organizational Citizenship Behavior Individual (OCBI) yang menekankan keuntungan organisasional secara tidak langsung yang mengacu pada individual seperti berperilaku sopan kepada rekan kerja atau membantu rekan kerja dengan masalah yang berhubungan dengan pekerjaan. Kemudian Organizational Citizenship Behavior Organization (OCBO) berkaitan pada perilaku yang menunjukkan kesadaran, dedikasi pekerjaan, dan loyalitas, yang secara langsung berkontribusi pada efektivitas dan kesuksesan organisasi, seperti mendukung perubahan dalam organisasi atau mempromosikan organisasi kepada orang luar. Karyawan mungkin terlibat dalam $O C B$ dengan 
Aziz Yogatama \& Dwiarko Nugrohoseno. Pengaruh Authentic Leadership terhadap CustomerOriented Organizational Citizenship Behavior dan Service Recovery Performance melalui Job Crafting dan HR Flexibility

berdedikasi dengan inisiatif atau solusi mereka bagi tujuan organisasi, atau membantu stakeholder organisasi seperti kolega atau konsumen (Luu, 2020). Customer-oriented OCB adalah serangkaian perilaku individu tertentu yang melampaui peran kerja untuk meningkatkan pelayanan serta kepuasan pelanggan, kemudian karyawan mungkin dapat melayani atau membantu pelanggan di luar peran mereka dalam pekerjaan seperti mengatasi kebutuhan dan keinginan pelanggan, menyesuaikan layanan, atau menemukan cara untuk meningkatkan layanan yang diberikan kepada pelanggan (Dimitriades, 2007). Qiu et al. (2019) menyebutkan authentic leaders dapat mempromosikan OCB karyawan karena pemimpin sejati memimpin dengan memberi teladan karena mereka menunjukkan kepercayaan diri, harapan, dan optimisme di tempat kerja (Avolio \& Gardner, 2005). Sikap dan emosi positif ini dapat menular dan menciptakan efek tetesan ke bawah yang positif melalui organisasi untuk mendorong perkembangan emosional dan kognitif yang positif di antara pengikut mereka, menghasilkan lebih banyak perilaku OCB (Fredrickson, 2003).

\section{Service Recovery Performance}

Lingkungan yang kompetitif saat ini memiliki basis pelanggan yang loyal akan meningkatkan pendapatan, dapat mengurangi biaya, membangun pangsa pasar, meningkatkan laba, dan tidak menutup kemungkinan, peran penting kualitas dan keunggulan layanan dalam implementasi program pemasaran dan manajemen layanan dilakukan dengan baik (Parasuraman et al., 1996; Schneider et al., 1998). Pada studi sebelumnya, Maxham \& Netemeyer (2002) menunjukkan hubungan positif dapat terjadi bahkan saat pemulihan yang bersifat tidak memuaskan diikuti dengan pemulihan yang memuaskan. Service recovery performance didefinisikan sebagai persepsi karyawan lini depan terhadap kemampuan dan tindakan dari dalam diri untuk mengatasi kegagalan layanan terhadap kepuasan konsumen. Perlu dicatat bahwa kinerja karyawan dapat digolongan oleh sejumlah ukuran termasuk hasil kualitas layanan yang dirasakan pelanggan, kepuasan pelanggan, dan indikator kinerja tradisional lainnya. Misalnya, pengawasan berdasarkan perilaku dan/atau hasil, penilaian rekan, atau penilaian diri (Babakus et al., 2003). Penelitian Hübner et al. (2018) menunjukkan ketertarikan pada service recovery performance dalam konteks $\mathrm{B} 2 \mathrm{~B}$ (business to business) karena kegagalan layanan memiliki pengaruh yang lebih besar dalam konteks ini. Tidak hanya berdampak pada operasional pelanggan B2B tetapi juga melalui penyebaran pengaruh rantai pasokan mereka melalui efek domino (Zhu \& Zolkiewski, 2015). Ketika karyawan lini depan dapat melayani pelanggan di luar apa yang telah ditugaskan serta berusaha untuk memulihkan kepuasan layanan melalui kinerja pemulihan layanan, karyawan mempresentasikan tanggung jawab sosialnya untuk menawarkan sumber daya yang dimiliki kepada karyawan (Luu et al., 2019).

\section{Hubungan antar Variabel}

Luu (2020) menyebutkan bahwa authentic leadership memiliki pengaruh positif terhadap Co-OCB, ditunjukkan melalui pemimpin yang dapat memberikan pengaruh terhadap perilaku OCB karyawan penjualan. Penelitian lebih lanjut melaporkan bahwa perilaku inovatif dan kreativitas di antara karyawan dapat dapat dijalankan melalui perilaku OCB (Xerri \& Brunetto, 2013). Pernyataan tersebut sejalan dengan $\mathrm{Wu}$ et al. (2013) yang menunjukkan adanya pengaruh siginifikan pada servant leadership terhadap Co-OCB. Wong et al. (2015) juga menunjukkan adanya hubungan positif antara service leadership dan customer orientation. Observasi dilakukan pada beberapa cabang perusahaan ternyata menunjukkan pemimpin mereka memiliki ciri-ciri perilaku authentic leadership namun dalam implementasinya kurang dapat memberikan pengaruh terhadap perilaku $C o-O C B$ karyawan penjualan maupun customer service.

\section{H1: Authentic leadership berpengaruh signifikan positif terhadap customer-oriented OCB.}

Terlepas dari sentralitas ide-ide authentic leadership terhadap literatur branding layanan, sedikit perkembangan teori membahas pengaruh kepemimpinan pada service recovery performance (SRP) karyawan yang selaras dengan nilai-nilai merek (Punjaisri et al., 2013). Penelitian sebelumnya menunjukkan adanya pengaruh positif pada authentic leadership terhadap service recovery performance dalam konteks $\mathrm{B} 2 \mathrm{~B}$, namun peran dari pemimpin penjualan dalam memerbaiki kegagalan layanan bagaimana pemimpin penjualan dapat memengaruhi kinerja karyawan penjualan 
belum dijelaskan dengan baik (Luu, 2020). Luo et al. (2019) dan Punjaisri et al. (2013) menunjukkan transformasional leadership memiliki pengaruh signifikan positif terhadap service recovery performance. Buljac-Samardzic \& van Woerkom (2015) mengungkapkan pemimpin yang memiliki peran sebagai coach kemungkinan besar akan merangsang kinerja tim dengan mendorong refleksi tim. Menurut Wijayati et al. (2020) coaching memiliki hubungan positif terhadap employee performance namun tidak memerkuat hubungan tersebut ketika dimoderasi dengan adanya coworking support. Bienstock et al. (2003) menemukan hubungan antara OCB pada tahap lebih lanjut di mana pelayanan dilakukan berdasarkan pelayanan standar pada organisasi. Pengamatan dilakukan pada cabang perusahaan menunjukkan pemimpin memiliki karakteristik authentic leadership yang selalu ditampilkan pada karyawan customer service dan karyawan penjualan, namun tidak sedikit juga pelanggan yang masih kurang puas terhadap kinerja pelayanan yang ada. Beberapa karyawan penjualan juga mengungkapkan pemimpin mereka kurang memberikan masukan-masukan yang bersifat membangun agar menciptakan layanan yang lebih baik secara individu.

\section{H2: Authentic leadership berpengaruh signifikan positif terhadap service recovery performance.}

Qiu et al. (2019) menyebutkan bahwa yang dilakukan oleh pemimpin otentik mempromosikan OCB karyawan karena alasan berikut. Pertama, pemimpin sejati memimpin dengan memberi teladan karena mereka menunjukkan kepercayaan diri, harapan, dan optimisme di tempat kerja (Avolio \& Gardner, 2005). Sikap dan emosi positif ini dapat menular dan menciptakan efek tetesan ke bawah yang positif melalui organisasi untuk mendorong perkembangan emosional dan kognitif yang positif di antara pengikut mereka, menghasilkan lebih banyak perilaku OCB (Fredrickson, 2003). Kedua, pemimpin otentik secara objektif mengevaluasi semua informasi yang relevan saat membuat keputusan; mereka menciptakan lingkungan yang adil dan terbuka di tempat kerja di mana karyawan lebih sadar akan pentingnya membantu orang lain dan didorong untuk melakukannya (Walumbwa et al., 2008). Ketiga, pemimpin otentik memiliki standar dan nilai moral internal yang tinggi, mereka mewakili model peran untuk memberikan isyarat dan panduan perilaku bagi pengikut untuk ditiru (Bandura, 1997). Literatur terkini oleh Van Vaerenbergh \& Orsingher (2016) menuntut fokus tambahan pada model pemulihan layanan secara jelas untuk memerhitungkan pengaruh organisasi pada perilaku pemulihan layanan tenaga kerja karena peranan pemimpin penjualan dalam membantu karyawan penjualan mengatasi pemulihan kegagalan layanan pada konteks B2B tidak didefinisikan secara jelas.

H3: Customer-oriented OCB berpengaruh signifikan positif dalam memediasi authentic leadership dan service recovery perfomance.

Melalui pandangan teori conservation of resource (COR), pemimpin penjualan otentik memiliki fungsi sebagai sumber daripada berbagai sumber Braun \& Nieberle (2017). Dalam penelitian Luu (2020), karyawan penjualan dapat menarik secara proaktif dalam memeroleh sumber daya lebih sebagai investasi dan keterlibatan mereka dalam pelanggan. Customer-oriented OCB secara signifikan memediasi hubungan antara authentic leadership terhadap service recovery performance. Delić et al. (2017) menyatakan dalam sumber daya dan tantangan mencari dan belajar dari lingkungan yang dibangun oleh pemimpin otentik. Karyawan penjualan melihat tantangan tersebut sebagai peluang dan melibatkan dirinya kedalam tantangan untuk meningkatkan kekosongan pelayanan mereka. Pemimpin otentik juga memanfaatkan sumber daya pribadi yang positif untuk berkontribusi dan melengkapi sumber daya pengikut mereka (Luthans \& Avolio, 2003). Berdasarkan pengamatan yang dilakukan pada karyawan beberapa cabang perusahaan, pemimpin secara otentik memberikan kebebasan karyawan untuk berperilaku job crafting untuk mengerjakan tugas-tugas yang ada, namun tidak menutup kemungkinan masih terjadi kegagalan dalam pelayanan. Ketika adanya pelanggan yang masih belum puas dengan pelayanan pada saat terjadinya hard complaint, customer service juga akan meminta bantuan pemimpin mereka, tetapi solusi yang diberikan hanya berdampak sedikit saja dalam proses pelayanan. Guchait et al. (2016) menunjukkan adanya hubungan positif antara supervisor support terhadap service recovery performance. 
Aziz Yogatama \& Dwiarko Nugrohoseno. Pengaruh Authentic Leadership terhadap CustomerOriented Organizational Citizenship Behavior dan Service Recovery Performance melalui Job Crafting dan HR Flexibility

H4: Job crafting berpengaruh signifikan positif dalam memediasi hubungan antara authentic leadership dan customer-oriented OCB.

n Luu (2020) menunjukkan customer-oriented $O C B$ memberikan pengaruh positif dalam memediasi hubungan antara authentic leadership dan service recovery performance. Bravo (2018) menyatakan keotentikan sebagai standar perilaku. Pemimpin otentik cenderung mengartikan dan berempati dengan tuntutan pekerjaan yang dihadapi pengikut mereka di mana karyawan penjualan cenderung mencari dukungan dan nasihat dari para pemimpin dan rekan kerja tentang cara menangani tuntutan kognitif dan emosional dalam proses job crafting. Pemimpin penjualan otentik sebagai sumber daya. Karyawan penjualan cenderung proaktif mencari sumber daya struktural dan sosial serta tantangan untuk pekerjaan layanan dan mencari bagaimana cara mengurangi tuntutan pekerjaan yang menghalangi pekerjaan mereka (Luu, 2020). Gordon et al. (2015) mengungkapkan bahwa umpan balik dari manajer mungkin saja memicu adanya umpan balik pada perilaku yang dicari di antara karyawan. Delić et al. (2017) mengungkapkan pembelajaran sanksi authentic leaders dapat mengaktifkan keterbukaan dan apresiasi terhadap karyawan penjualan terhadap pengetahuan dan umpan balik tentang customer service performance dari tim penjualan dan dari pelanggan. Selain itu menyadari keterbatasan tim mereka sehubungan dengan pengetahuan, keterampilan dan peluang (Lyubovnikova et al., 2017). Berdasarkan observasi yang telah dilakukan pada cabang perusahaan, pada saat pandemi Covid-19 karyawan dapat bekerja sesuai dengan kapabilitas masing-masing dalam mengerjakan berbagai tugas, berpikir secara kreatif dan bertindak proaktif sesuai dengan deskripsi pekerjaan yang ditentukan. Sehingga mereka dapat melakukan service recovery performance secara cepat apabila mengalami kendala dalam layanan.

H5: Job crafting berpengaruh signifikan positif dalam memediasi hubungan antara authentic leadership dan service recovery performance.

Authentic leadership dan HR flexibility merupakan dua sumber dari sumber karyawan penjualan pada customer service performance (Braun \& Nieberle, 2017). Luu (2020) menunjukkan HR flexibility berhasil memoderasi hubungan antara authentic leadership dan job crafting dalam konteks tingkat $H R$ flexibility yang rendah. Liu et al. (2013) dalam penelitiannya menunjukkan kolektivisme HRM secara pisitif memoderasi peran leadership style. Namun penelitian Kalshoven \& Boon (2012) menunjukkan pengaruh signifikan negatif pada efek moderasi sistem HRM. Berdasarkan COR theory dari Hobfoll (2001), authentic leadership dan HR flexibility sebagai fungsi contextual resource yang mungkin dapat menyediakan sebagai pengganti satu sama lain dalam pengaruhnya terhadap job crafting di antara karyawan penjualan. Karyawan dapat merespon dengan kuat terhadap pemimpin ketika bertindak sebagai pemikul sumber daya yang kuat dan sumber daya kontekstual lainnya, misalnya situasi sumber daya yang lebih rendah atau lebih jauh untuk dijangkau karena pemimpin otentik sangat peduli dalam membangun kekuatan karyawan dan memerluas pemikiran mereka (Avolio \& Gardner, 2005; Rahimnia \& Sharifirad, 2015). Ketika praktik SDM tidak mencerminkan investasi organisasi pada keterampilan karyawan penjualan dan fleksibilitas perilaku, karyawan penjualan cenderung lebih kuat menanggapi perilaku otentik pada pemimpin penjualan mereka dengan terlibat dalam perilaku pembuatan tugas untuk meningkatkan kinerja layanan mereka (Luu, 2020). Hasil wawancara pada karyawan perusahaan menunjukkan pada saat pandemi karyawan ditugaskan oleh pemimpin mereka untuk tetap melakukan layanan dengan perilaku karyawan secara job crafting walaupun karyawan tersebut sedang melakukan work from home (WFH). Beberapa karyawan juga menyatakan bahwa tingkat fleksibilitas SDM di perusahaan ini tinggi karena sering terjadi pergantian karyawan atau pindah tugas ke cabang lain sehingga karyawan dituntut untuk secara cepat beradaptasi dengan lingkungan kerja yang baru.

H6: HR flexibility berpengaruh signifikan positif dalam memoderasi hubungan antara authentic leadership dan job crafting. 


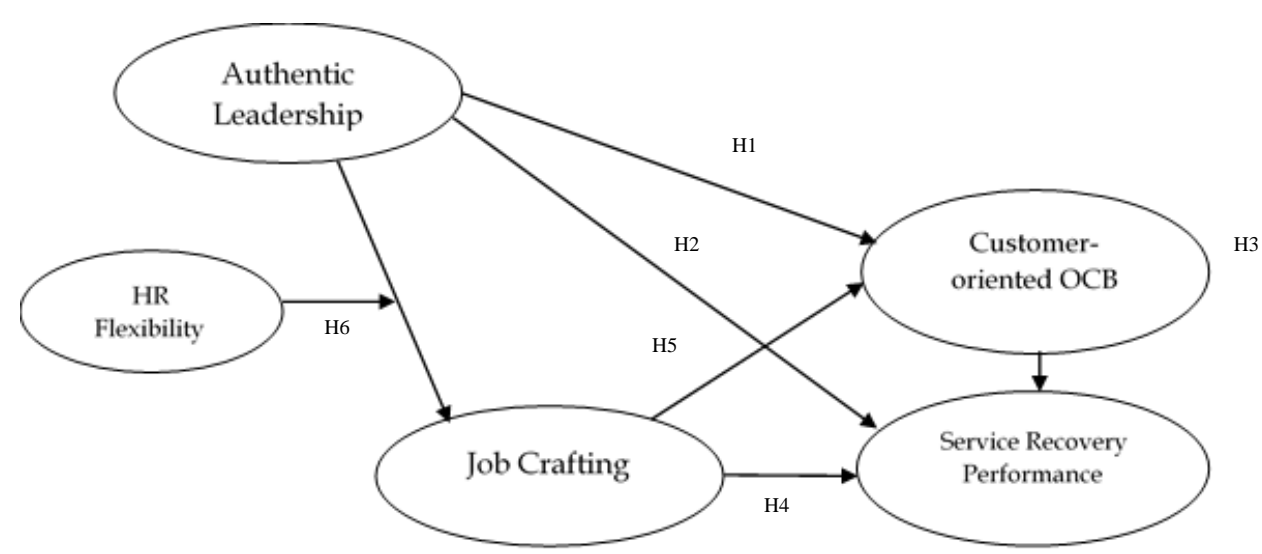

Gambar 1. KERANGKA KONSEPTUAL

\section{METODE PENELITIAN}

Studi ini menggunakan metode kuantitatif dengan penentuan sampel dipilih menggunakan purposive sampling. Sebanyak 95 orang karyawan PT. Telkom Indonesia (Persero) di wilayah Surabaya berpartisipasi dalam survey ini menggunakan Google Form dengan rincian 60 orang customer-service (63\%), 30 orang karyawan penjualan (sales) (32\%) dan 5 orang sales manager (SPV) (5\%). Sebanyak $67 \%$ karyawan berjenis kelamin perempuan dan 33\% laki-laki dengan masa jabatan 1 tahun hingga lebih dari 6 tahun. Analisis statistik yang digunakan pada studi ini menggunakan Structural equation modeling (SEM) dengan aplikasi SmartPLS versi 3.0.

\section{HASIL DAN PEMBAHASAN}

Tabel 1. deskripsi statistik data penelitian dengan menggunakan rerata dan deviasi standar sebagai bahan penyusun titik kategori. Syarat penggunaan strategi statistik hipotetik yaitu menggunakan alat ukur sebagai acuan. Tinggi rendahnya skor subjek tergantung dari posisi pada rentang skor yang memungkinkan diperoleh pada sebuah alat ukur (Widhiarso, 2010).

Tabel 1.

MEAN HIPOTETIK DAN DEVIASI STANDAR

\begin{tabular}{|c|c|c|c|c|}
\hline Variabel & Mean & Deviasi Standar & Kategori & Jumlah Responden \\
\hline & & \multirow{3}{*}{10,67} & Rendah & 1 \\
\hline \multirow{3}{*}{ Authentic Leadership } & \multirow{3}{*}{48} & & Sedang & 2 \\
\hline & & & Tinggi & 92 \\
\hline & & \multirow{4}{*}{14} & Rendah & 1 \\
\hline \multirow{3}{*}{ HR Flexibility } & \multirow[t]{3}{*}{63} & & Sedang & 3 \\
\hline & & & Tinggi & 91 \\
\hline & & & Rendah & 0 \\
\hline \multirow[t]{3}{*}{ Job Crafting } & \multirow[t]{3}{*}{63} & \multirow[t]{3}{*}{14} & Sedang & 5 \\
\hline & & & Tinggi & 90 \\
\hline & & & Rendah & 0 \\
\hline \multirow[t]{2}{*}{ Customer-oriented $O C B$} & \multirow[t]{2}{*}{28} & \multirow[t]{2}{*}{7} & Sedang & 3 \\
\hline & & & Tinggi & 92 \\
\hline \multirow{3}{*}{$\begin{array}{c}\text { Service Recovery } \\
\text { Performance }\end{array}$} & \multirow{3}{*}{15} & \multirow{3}{*}{3,34} & Rendah & 0 \\
\hline & & & Sedang & 5 \\
\hline & & & Tinggi & 90 \\
\hline
\end{tabular}

Sumber: Output IBM SPSS Statics 25 (2021, data diolah)

Tabel 1. menjelaskan tingkat subjek penelitian dari responden terhadap masing-masing variabel. Satu orang responden memiliki kategori rendah terhadap variabel authentic leadership. Pada HR flexibility sebanyak satu orang memiliki kategori yang rendah. Kategori sedang, sebanyak dua orang pada variabel authentic leadership, tiga orang pada variabel HR Flexibility, lima orang terhadap variabel 
Aziz Yogatama \& Dwiarko Nugrohoseno. Pengaruh Authentic Leadership terhadap CustomerOriented Organizational Citizenship Behavior dan Service Recovery Performance melalui Job Crafting dan HR Flexibility

job crafting dan lima orang terhadap variabel service recovery perfomance. Subjek penelitian pada kategori tinggi yaitu variabel authentic leadership sebanyak 92 orang responden, HR flexibility sebanyak 91 orang, variabel job crafting sebanyak 90 orang, dan service recovery performance sebanyak 90 orang.

Secara umum, karyawan perusahaan ini memiliki motivasi tinggi dalam memahami subjek penelitian di mana sebagian besar hasil menunjukkan kategori tinggi. Sebanyak satu responden menunjukkan kategori rendah berdasarkan penilaian kategori yang mengindikasikan perlunya peningkatan wawasan dan pelatihan bagi karyawan yang memiliki pemahaman kategori rendah. Sedangkan beberapa karyawan yang memiliki kategori sedang akan lebih baik jika ditingkatkan kemampuan pemahaman dasarnya.

\section{Uji Validitas}

Pengujian validitas dilakukan untuk mengetahui valid atau tidaknya item pernyataan (Ghozali, 2006). Setiap indikator pada masing-masing variabel penelitian ini sudah memenuhi nilai validitas dengan nilai outer loadings yang lebih besar dari 0,50 . Model konstruk bisa dikatakan valid apabila nilai seluruh indikator memenuhi convergent validity.

\section{Composite Reliability}

Pengujian suatu nilai dalam reliabilitas antara blok indikator dengan konstruk dalam variabel yaitu dengan menggunakan composite reliability. Reliabilitas data dikatakan baik apabila memiliki nilai di atas 0,70. Variabel authentic leadership memiliki nilai composite reliability sebesar 0,918. $H R$ flexibility sebesar 0,919 serta job crafting sebesar 0,862. Nilai customer-oriented OCB beserta service recovery performance memiliki nilai composite reliability masing-masing sebesar 0,820 dan 0,849 .

\section{Cronbach's Alpha}

Hasil Cronbach's alpha dapat meningkatkan composite reliability, hasil pengujian menunjukkan nilai pada masing-masing variabel dikatakan terbukti dan menghasilkan nilai di atas 0,60 dengan rincian variabel authentic leadership sebesar 0,865, HR flexibility sebesar 0,890. Job crafting menunjukkan nilai sebesar 0,787 sedangkan customer-oriented $O C B$ dan service recovery performance memiliki masing-masing nilai sebesar 0,708 dan 0,644 .

\section{R-Square}

Tabel 2 menjelaskan nilai $R$-square. Model pengaruh authentic leadershp bagi customer-oriented $O C B$ menghasilkan koefisien $R$-Square sebanyak 0,354 dengan interpretasi variabel konstruk customer-oriented $O C B$ dapat dijelaskan oleh variabel authentic leadership sebesar 35,4\%. Kemudian sebesar 64,6\% dijelaskan oleh variabel lain di luar studi ini. Nilai koefisien $R$-Square dari pengaruh authentic leadership terhadap job craftng sebesar 62,6\%, sedangkan sebesar 37,4\% dijelaskan faktor lain di luar penelitian ini. Pengaruh authentic leadership terhadap service recovery performance memiliki hasil koefisien $R$-Square 0,503. Jika diinterpretasikan dalam variabel konstruk service recovery performance dapat dijelaskan oleh authentic leadership sebesar 50,3\%, sedangkan sebesar 49,7\% dapat dijelaskan oleh variabel - variabel lain yang tidak ada dalam penelitian ini.

Tabel 2.

\section{R-SQUARE}

\begin{tabular}{cc}
\hline Variabel & R-Square \\
\hline Authentic Leadership & \\
Customer-oriented OCB & 0,354 \\
Job Crafting & 0,626 \\
Service recovery performance & 0,503 \\
\hline
\end{tabular}

Sumber: Output SmartPLS 3.0 (2020, data diolah) 


\section{Uji Kausalitas}

Inner model digunakan untuk melihat hubungan dari variabel pada path coefficient dan hasil indirect effects. Nilai path coefficient pada tabel 3 menunjukkan hipotesis 1 dan hipotesis 2 ditolak karena nilai $t$-statistics yang dihasilkan sebesar 0,371 dan 1,803 kurang dari 1,96. Sedangkan hasil indirect effect pada Tabel 3 menunjukkan hipotesis 3 ditolak dengan nilai $t$-statistics yang kurang dari 1,96 yaitu sebesar 0,369. Hasil dari hipotesis 4 memiliki nilai 1,990 yang berarti diterima dan hipotesis 5 diterima karena memiliki nilai $t$-statistics lebih dari 1,96 dengan nilai 2,274 yang artinya job crafting mampu memediasi hubungan antara authentic leadership terhadap customer-oriented OCB begitu juga dengan service recovery performance. Hasil dari hipotesis 6 ditolak, path coefficient menunjukkan variabel HR Flexibility tidak terbukti memoderasi hubungan antara authentic leadership dan job crafting memiliki nilai $t$-statistic sebesar 0,917.

Tabel 3. PATH COEFFICIENTS DAN INDIRECT EFFECT

\begin{tabular}{lcccc}
\hline \multicolumn{1}{c}{ Hubungan antar Variabel } & $\begin{array}{c}\text { Original } \\
\text { Sample }\end{array}$ & T-Statistic & P-Value & Keterangan \\
\hline $\begin{array}{l}\text { Authentic Leadership } \rightarrow \text { Customer- } \\
\text { oriented OCB }\end{array}$ & $-0,083$ & 0,371 & 0,211 & $\begin{array}{c}\text { Tidak } \\
\text { Signifikan } \\
\text { Authentic Leadership } \rightarrow \text { Service }\end{array}$ \\
$\begin{array}{l}\text { Recovery Performance } \\
\text { Authentic Leadership } x \text { HR }\end{array}$ & $-0,295$ & 1,803 & 0,072 & $\begin{array}{c}\text { Signifikan } \\
\text { Tidak }\end{array}$ \\
$\begin{array}{l}\text { Flexibility } \rightarrow \text { Job crafting } \\
\text { Authentic Leadership } \rightarrow \text { Customer- } \\
\text { oriented OCB } \rightarrow \text { Service recovery }\end{array}$ & 0,042 & 0,917 & 0,360 & Signifikan \\
performance & $-0,039$ & 0,369 & 0,713 & $\begin{array}{c}\text { Tidak } \\
\text { Authentic Leadership } \rightarrow \text { Job }\end{array}$ \\
$\begin{array}{l}\text { Crafting } \rightarrow \text { Customer-oriented OCB } \\
\text { Authentic Leadership } \rightarrow \text { Job } \\
\text { Crafting } \rightarrow \text { Service Recovery }\end{array}$ & 0,372 & 1,990 & 0,047 & Signifikan \\
Performance & 0,289 & 2,274 & 0,023 & Signifikan \\
\hline Sur & & & & \\
\hline
\end{tabular}

Sumber: Output SmartPLS 3.0 (2020, data diolah)

\section{Pengaruh Authentic Leadership terhadap Customer-oriented OCB}

Pengujian path coefficient menunjukkan bahwa authentic leadership tidak berpengaruh signifikan terhadap customer-oriented $O C B$ yang berarti $\mathrm{H} 1$ ditolak. Hasil penelitian ini mendukung penelitian Ekowati et al. (2013) yang menyatakan tranformational leadership ternyata juga tidak memengaruhi $O C B$ karena kepemimpinan memberikan efektivitas jika didukung oleh perilaku yang kompeten seperti memerhatikan bawahan, menjalin komunikasi yang baik, memberdayakan dan mengembangkan karyawan serta memotivasi karyawan. Mackenzie et al. (2001) mencatat bahwa stimulasi intelektual pada transformasional leadership diperkirakan memiliki hubungan negaif dengan $O C B$ karena tekanan yang diberi secara terus menerus untuk memikirkan cara-cara baru kemungkinan menyebabkan karyawan memikirkan peran inti daripada peran ekstra di luar pekerjaan seharusnya.

Dibuktikan dari karyawan penjualan perusahaan ini khususnya pada cabang Plaza Telkom bekerja dalam konteks B2C (business to consumer) di mana mereka melayani pelanggan secara langsung sesuai apa yang dikeluhkan. Namun dalam tugasnya, authentic leaders tidak secara langsung terlibat terhadap tugas karyawan dalam melaksanakan customer-oriented OCB. Karyawan hanya diminta untuk melaksanakan tugas sesuai dengan ketentuan pemimpin dan diberi kebebasan cara untuk berperilaku $O C B$ di luar pekerjaan mereka. Ketika pelanggan menyuarakan ketidakpuasan, mereka dapat menawarkan kritik yang membangun, memungkinkan penyedia layanan untuk memerbaiki masalah, atau merusak reputasi perusahaan dengan kata-kata negatif dari mulut ke mulut (Hansen et al., 1996). Sehingga, keterampilan (skill) karyawan dalam melayani pelanggan sesuai dengan ketentuan dan prosedur perusahaan sangat diperlukan secara langsung untuk membantu permasalahan 
Aziz Yogatama \& Dwiarko Nugrohoseno. Pengaruh Authentic Leadership terhadap CustomerOriented Organizational Citizenship Behavior dan Service Recovery Performance melalui Job Crafting dan HR Flexibility

pelanggaan. Hasil penelitian ini mendukung penelitian Luu (2020) bahwa authentic leadership dapat memberikan pengaruh terhadap customer-oriented OCB dalam konteks B2B.

\section{Pengaruh Authentic Leadership terhadap Service Recovery Performance}

Hasil pengujian diketahui bahwa authentic leadership memiliki pengaruh tidak signifikan terhadap service recovery performance sehingga $\mathrm{H} 2$ ditolak. Hal ini karena peran authentic leadership akan berpengaruh pada service recovery performance apabila dalam konteks B2B (Luu, 2020). Diperkuat dengan penelitian Vanvaerenbergh \& Orsingher, (2016) yang menyebutkan peran authentic leadership akan lebih efektif untuk menyelesaikan masalah kegagalan dalam layanan (service failure) yang menuntut fokus dalam memerhitungkan pengaruh perilaku service recovery performance pada karyawan. Peran pemimpin penjualan dalam menututupi kegagalan layanan dalam konteks B2B serta perilakunya yang dapat memengaruhi kinerja karyawan penjualan dalam melakukan pelayanan (Luu, 2020). Namun penelitian ini juga tidak mendukung hasil Guchait et al. (2016) yang menunjukkan adanya hubungan positif antara supervisor support terhadap service recovery performance dan Luo et al. (2019) yang menunjukkan adanya hubungan positif antara trasnformational leadership terhadap service recovery performance.

Berdasarkan hasil wawancara dengan beberapa karyawan di beberapa cabang perusahaan menunjukkan bahwa peran authentic leadership dirasa cukup kurang membantu dalam mengatasi kegagalan layanan karena pelayanan yang bersifat B2C karena peran pemimpin hanya akan membantu apabila terjadi kegagalan layanan yang tidak dapat diatasi oleh karyawan penjualan maupun karyawan customer service.

\section{Pengaruh Authentic Leadership terhadap Service Recovery Performance melalui Customer oriented $O C B$}

Pengujian menunjukkan hasil bahwa customer-oriented $O C B$ dalam memediasi hubungan antara authentic leadership terhadap service recovery performance memiliki pengaruh tidak signifikan yang berarti H3 ditolak. Didukung Kalshoven \& Boon (2012) customer-oriented OCB akan lebih memediasi peran authentic leadership apabila pelayanan dilakukan dalam berdasarkan business oriented. Karakteristik OCB merupakan perilaku yang bukan bersifat atas dasar perintah orang lain, namun dari kesadaran karyawan itu sendiri untuk berinteraksi dengan pelanggan, melayani kebutuhannya, serta membuat pelanggan secara langsung menjadi sangat penting bagi karyawan (Bienstock et al., 2003:362). Hasil penelitian ini tidak sejalan dengan penelitian Luu (2020) yang menunjukkan adanya pengaruh mediasi customer-oriented $O C B$ terhadap hubungan antara authentic leadership dan service recovery perfromance

Berdasarkan observasi yang telah dilakukan di beberapa cabang perusahaan ini menunjukkan pada saat tejadinya pandemi Covid-19 kemampuan service recovery performance sangat bergantung dari karyawan untuk melayani keluhan pelanggan terhadap jaringan secara cepat. Pada saat terjadinya kegagalan layanan terhadap pelanggan, SPV secara otentik memberikan masukan-masukan positif untuk membantu karyawan mengatasi kegagalan layanan tersebut. Namun tidak sedikit juga pelanggan yang masih mengalami ketidakpuasan tehadap layanan diberikan karena karyawan customer service juga diharuskan melayani keluhan-keluhan pelanggan lain baik pelanggan yang melakukan complaint di tempat, via telepon, dan pelanggan yang melakukan complaint melalui karyawan penjualan.

\section{Pengaruh Authentic Leadership terhadap Customer-oriented OCB melalui Job Crafting}

Hasil pengujian hipotesis menunjukkan job crafting memiliki pengaruh signifikan dalam memediasi hubungan antara authentic leadership terhadap customer-oriented OCB sehingga dikatakan $\mathrm{H} 4$ diterima. Hasil ini mendukung penelitian Luu (2020) peran job crafting dalam memediasi authentic leadership dan Co-OCB. Hasil juga didukung oleh Braun \& Nieberle, (2017) bahwa peran authentic leaders mungkin saja menyediakan sumber dari segala sumber di mana karyawan penjualan dapat memprediksi untuk mengambil strategi sumber daya secara proaktif seperti job crafting untuk mendapatkan lagi sumber daya, pengalaman, dan mengumpulkan perilaku sumber daya di atas 
ekspetasi yang rendah seperti customer-oriented $O C B$ dan pelayanan (Halbesleben et al., 2014; Stoverink et al., 2018). Hasil wawancara terhadap beberapa karyawan yang menunjukkan SPV memberikan kebebasan untuk melakukan pekerjaan secara kreatif dan proaktif agar pekerjaanpekerjaan yang telah diberikan dan dapat mendorong karyawan untuk selalu berorientasi pada pelanggan.

\section{Pengaruh Authentic Leadership terhadap Service Recovery Performance melalui Job Crafting}

Hasil menunjukkan bahwa job crafting berpengaruh signifikan dalam memedasi hubungan antara authentic leadership terhadap service recovery performance sehingga H5 diterima. Didukung penelitian terdahulu Braun \& Nieberle (2017) yang menyatakan authentic sales leadership berpengaruh positif terhadap service performance areas dan Wong et al. (2015) yang membahas instrumen mediasi perilaku yang menciptakan pelayanan yang lebih baik seperti adaptive selling dan learning behavior (Guchait et al., 2016). Penelitian ini mendukung Luu (2020) bahwa karyawan penjualan cenderung mencari dukungan dan saran dari pemimpin dan teman-teman bagaimana cara menangani tuntutan kognitif maupun emosional dalam proses job crafting. Bekerja dengan authentic leaders dapat membantu karyawan dalam menyusun job crafting dengan cara mencari sumber daya struktural dan sosial, serta menemukan cara untuk mengurangi tuntutan pekerjaan dalam job crafting.

\section{Pengaruh HR Flexibility dalam Memoderasi Hubungan antara Authentic Leadership dengan Job Crafting}

Pengujian path coefficient menunjukkan hasil HR flexibility tidak terbukti memoderasi hubungan authentic leadership dan job crafting yang berarti H6 ditolak. Berdasarkan hasil wawancara beberapa karyawan di perusahaan, memang tingkat fleksibilitas di perusahaan tergolong tinggi yang ditandai dengan karyawan yang memiliki kemampuan untuk mendapatkan keterampilan yang diperlukan agar dapat ditugaskan ke berbagai peran kerja. Dari segi organisasional perusahaan dapat secara efektif menugaskan kembali karyawan ke jenis pekerjaan yang membutuhkan keterampilan yang berbeda. Selain itu perusahaan juga sering melakukan perpindahan karyawan pada cabang perusahaan lain agar distribusi SDM merata dan sesuai dengan apa yang dibutuhkan perusahaan. Hal ini mendukung penelitian dari Kalshoven \& Boon (2012) yang menyatakan HRM dengan konteks fleksibilitas yang tinggi tidak memiliki pengaruh dalam memoderasi hubungan ethical leadership. Namun hasil penelitian ini juga tidak mendukung penelitian Luu (2020) yang membuktikan HR flexibility memoderasi hubungan antara authentic leadership dan job crafting dengan tingkat fleksibilitas yang rendah dan temuan Liu et al. (2013) yang menyebutkan kolektivisme HRM memiliki hubungan positif memoderasi peran leadership style.

\section{KESIMPULAN}

Penelitian ini mendeskripsikan variabel authentic leadership tidak memiliki pengaruh pada customeroriented $O C B$ dan service recovery performance pada karyawan penjualan PT. Telkom Indonesia (Persero) wilayah Surabaya. Dari hasil tersebut, peran authentic leadership kurang memberikan dampak bagi karyawan. Namun dengan mediasi job crafting peran authentic leadership berpengaruh positif terhadap customer-oriented $O C B$ dan service recovery performance. Dengan bantuan job crafting karyawan akan menyederhanakan pekerjaannya untuk melayani secara efektif serta berorientasi pada pelanggan. HR flexibility tidak terbukti dalam memoderasi hubungan antara authentic leadership dan job crafting. Karyawan penjualan mengandalkan pemimpin yang otentik sebagai sumber daya utama pada saat tingkat fleksibilitas rendah. Namun apabila tingkat fleksibilitas tinggi, maka interaksi tidak memberikan pengaruh job crafting pada tingkat lebih tinggi.

Implikasi manajerial pada penelitian ini perusahaan dapat memberikan pelatihan lebih lanjut terhadap pemimpin yang memiliki sifat authentic leadership agar pelayanan perusahaan dalam konteks B2C dapat memberikan pengaruh yang efektif terhadap service recovery performance. Authentic leaders dalam memengaruhi job crafting karyawan kurang memberikan pengaruh pada kondisi tingkat $H R$ flexibility yang tinggi. Maka dari itu perusahaan perlu mengurangi adanya perpindahan tempat kerja karyawan sehingga authentic leaders dapat lebih fokus memberikan masukan-masukan yang bersifat 
Aziz Yogatama \& Dwiarko Nugrohoseno. Pengaruh Authentic Leadership terhadap CustomerOriented Organizational Citizenship Behavior dan Service Recovery Performance melalui Job Crafting dan HR Flexibility

membangun job crafting pada karyawan lebih lama pada masing - masing cabang perusahaan yang ada. Perusahaan perlu meningkatkan peran dalam memberikan pendidikan bukan hanya melalui pelatihan kerja, tapi lebih mengarah ke pendidikan yang bersifat organisasional. Misalnya pada saat karyawan mengalami kesulitan dalam pemenuhan tugas yang diberikan dan benar-benar membutuhkan peran pemimpin yang bersifat authentic leadership sehingga dapat memberikan pengaruh positif terhadap perilaku customer-oriented $O C B$ dan service recovery performance. Kemudian SPV harus membina dan mendorong karyawan penjualan dan customer service agar dapat membentuk pekerjaannya lebih mudah dan akurat sehingga memperoleh sumber daya terkait layanan lebih lanjut (pengetahuan, keterampilan, dan umpan balik). Pemberian reward juga akan bermanfaat bagi karyawan yang kreatif dalam melakukan job crafting serta memberi pelatihan lebih lanjut. Penelitian selanjutnya dapat meneliti di konteks B2C dan melibatkan bentuk variabel OCB dan bentuk variabel service performance yang lain.

\section{DAFTAR PUSTAKA}

Ashill, N. J., Rod, M., \& Carruthers, J. (2008). The Effect of Management Commitment to Service Quality on Frontline Employees 'Job Attitudes, Turnover Intentions and Service Recovery Performance in a New Public Management Context. Journal of Strategic Marketing, 16(5), 437-462. https://doi.org/10.1080/09652540802480944

Asmara, C. G. (2020). Daya Saing RI Melorot 8 Peringkat, RI Kalah Cepat? cnbcindonesia.com. https://www.cnbcindonesia.com/news/20200619092949-4-166485/daya-saing-ri-melorot-8peringkat-ri-kalah-cepat (diakses pada 23 November 2020)

Avolio, B. J., \& Gardner, W. L. (2005). Authentic Leadership Development: Getting to the Root of Positive Forms of Leadership. Leadership Quarterly, 16(3), 315-338. https://doi.org/10.1016/j.leaqua.2005.03.001

Babakus, E., Yavas, U., \& Avci, O. M. K. T. (2003). The Effect of Management Commitment to Service Quality on Employees' Affective and Performance Outcomes. Journal of the Academy of Marketing Science, 31(3), 272-286. https://doi.org/10.1177/0092070303253525

Bakker, A. B., Tims, M., \& Derks, D. (2012). Proactive Personality and Job Performance: The Role of Job Crafting and Work Engagement. Human Relation, 65(10), $1359-1378$. https://doi.org/10.1177/0018726712453471

Bandura, A. (1997). Self-Efficacy: The Exercise Of Control. New York: W.H. Freeman and Company.

Bavik, A., Bavik, Y. L., \& Tang, P. M. (2017). Servant Leadership , Employee Job Crafting , and Citizenship Behaviors : A Cross-Level Investigation. Cornell Hospitality Quarterly, 58(4), 364373. https://doi.org/10.1177/1938965517719282

Bhattacharya, M., Gibson, D. E., \& Doty, D. H. (2005). The Effects of Flexibility in Employee Skills, Employee Behaviors, and Human Resource Practices on Firm Performance. Journal of Management, 31(4), 622-640. https://doi.org/10.1177/0149206304272347

Bienstock, C. C., Demoranville, C. W., \& Smith, R. K. (2003). Organizational Citizenship Behavior and Service Quality. Journal of Services Marketing, 17(4), 357-378. https://doi.org/10.1108/08876040310482775

Braun, S., \& Nieberle, K. W. A. M. (2017). Authentic Leadership Extends Beyond Work: A Multilevel Model of Work-family Conflict and Enrichment. The Leadership Quarterly, April, 1-18. https://doi.org/10.1016/j.leaqua.2017.04.003 
Bravo, P. C. (2018). Authentic Leadership and Creativity. In International Journal of Productivity and Performance Management (Vol. 67, Issue 9). https://doi.org/10.1108/ijppm-02-2018-0082

Buljac-Samardzic, M., \& van Woerkom, M. (2015). Can Managers Coach Their Teams Too Much? Journal of Managerial Psychology, 30(3), 280-296. https://doi.org/10.1108/JMP-12-2012-0380

Delić, M., Slåtten, T., Milić, B., Marjanović, U., \& Vulanović, S. (2017). Fostering Learning Organisation in Transitional Economy - The Role of Authentic Leadership and Employee Affective Commitment. International Journal of Quality and Service Sciences, 34(1), 1-5.

Dimitriades, Z. S. (2007). The Influence of Service Climate and Job Involvement on Customeroriented Organizational Citizenship Behavior in Greek Service Organizations: a survey. Employee Relations, 29(5), 469-491. https://doi.org/10.1108/01425450710776290

Ekowati, V. M., Troena, E. A., \& Noermijati, N. (2013). Organizational Citizenship Behavior Role in Mediating the Effect of Transformational Leadership, Job Satisfaction on Employee Performance: Studies in PT Bank Syariah Mandiri Malang East Java. International Journal of Business and Management, 8(17), 1-12. https://doi.org/10.5539/ijbm.v8n17p1

Fredrickson, B. L. (2003). Positive Emotions and Upward Spirals in Organizations. (pp. 163-175) San Francisco, CA: Berrett-Koehler..

George, B. (2003). Authentic Leadership: Rediscovering the Secrets to Creating Lasting Value. San Francisco, California: Jossey-Bass.

George, B., Sims, P., McLean, A. N., \& Mayer, D. (2007). Discovering your Authentic Leadership. United States: Harvard Business Review, 85(2).

Ghozali, I. (2006). Structural Equation Modelling Metode Alternatif dengan Partial Least Square. Semarang: Universitas Diponegoro.

Gordon, H. J., Demerouti, E., Le Blanc, P. M., \& Bipp, T. (2015). Job Crafting and Performance of Dutch and American Health Care Professionals. Journal of Personnel Psychology, 14(4), 192 202. https://doi.org/10.1027/1866-5888/a000138

Guchait, P., Lee, C., Wang, C. Y., \& Abbott, J. L. (2016). Impact of Error Management Practices on Service Recovery Performance and Helping Behaviors in the Hospitality Industry: The Mediating Effects of Psychological Safety and Learning Behaviors. Journal of Human Resources in Hospitality and Tourism, 15(1), 1-28. https://doi.org/10.1080/15332845.2015.1008395

Halbesleben, J. R. B., Neveu, J. P., Paustian-Underdahl, S. C., \& Westman, M. (2014). Getting to the "COR": Understanding the Role of Resources in Conservation of Resources Theory. Journal of Management, 40(5), 1334-1364. https://doi.org/10.1177/0149206314527130

Hansen, S. W., Swan, J. E., \& Powers, T. L. (1996). The Perceived Effectiveness of Marketer Responses to Industrial Buyer Complaints: Suggestions for Improved Vendor Performance and Customer Loyalty. Journal of Business and Industrial Marketing, 11(1). https://doi.org/10.1108/08858629610112319

Hobfoll, S. E. (2001). The Influence of Culture, Community, and the Nested-self in the Stress Process: Advancing conservation of resources theory. Applied Psychology, 50(3), 337-421. https://doi.org/10.1111/1464-0597.00062

Hübner, D., Wagner, S. M., \& Kurpjuweit, S. (2018). The Service Recovery Paradox in B2B 
Aziz Yogatama \& Dwiarko Nugrohoseno. Pengaruh Authentic Leadership terhadap CustomerOriented Organizational Citizenship Behavior dan Service Recovery Performance melalui Job Crafting dan HR Flexibility

Relationships. Journal of Business and Industrial Marketing, 33(3), 291-302. https://doi.org/10.1108/JBIM-03-2016-0055

Joo, B. K., \& Jo, S. J. (2017). The Effects of Perceived Authentic Leadership and Core SelfEvaluations on Organizational Citizenship Behavior: The Role of Psychological Empowerment as a Partial Mediator. Leadership and Organization Development Journal, 38(3), 463-481. https://doi.org/10.1108/LODJ-11-2015-0254

Kalshoven, K., \& Boon, C. T. (2012). Ethical Leadership, Employee Well-Being, and Helping the Moderating Role of Human Resource Management. Journal of Personnel Psychology, 11(1), 60-68. https://doi.org/10.1027/1866-5888/a000056

Kernis, M. H. (2003). Toward a Conceptualization of Optimal Self-esteem. Psychological Inquiry, 14(1), 1-26. https://doi.org/10.1207/S15327965PLI1401_01

Liu, Z., Cai, Z., Shi, S., \& Fang, Y. (2013). Leadership Style and Employee Turnover Intentions : A Social Identity Perspective. Career Development International 18(3), 305-324. https://doi.org/10.1108/CDI-09-2012-0087

Luo, A., Guchait, P., Lee, L., \& Madera, J. M. (2019). Transformational Leadership and Service Recovery Performance: The Mediating Effect of Emotional Labor and the Influence of Culture. International Journal of Hospitality Management, 77, 31-39. https://doi.org/10.1016/j.ijhm.2018.06.011

Luthans, F., \& Avolio, B. (2003). Authentic Leadership Development. 1, 241-271. San Francisco, CA: Berrett-Koehler.

Luu, T. T. (2020). Linking Authentic Leadership to Salespeople's Service Performance: The Roles of Job Crafting and Human Resource Flexibility. Industrial Marketing Management, 84(May 2019), 89-104. https://doi.org/10.1016/j.indmarman.2019.06.002

Luu, T. T., Rajendran, D., Rowley, C., \& Cong, D. (2019). Journal of Hospitality and Tourism Management Customer Value Co-Creation in the Business-to-business Tourism Context: The Roles of Corporate Social Responsibility and Customer Empowering Behaviors. Journal of Hospitality and Tourism Management, 39(February), 137-149. https://doi.org/10.1016/j.jhtm.2019.04.002

Lyubovnikova, J., Legood, A., Turner, N., \& Mamakouka, A. (2017). How Authentic Leadership Influences Team Performance: The Mediating Role of Team Reflexivity. Journal of Business Ethics, 141(1), 59-70. https://doi.org/10.1007/s10551-015-2692-3

Mackenzie, S. B., Podsakoff, P. M., \& Rich, G. A. (2001). Transformational and Transactional Leadership and Salesperson Performance The Dangers of Poor Construct Conceptualization View project. Journal of the Academy of Marketing Science, 29(2), 115-134.

Maxham, J. G., \& Netemeyer, R. G. (2002). A Longitudinal Study of Complaining Customers' Evaluations of Multiple Service Failures and Recovery Efforts. Journal of Marketing, 66(4), 57-71. https://doi.org/10.1509/jmkg.66.4.57.18512

Meijerink, J., Bos-nehles, A., \& Leede, J. De. (2018). How Employees Pro-activity Translates HighCommitment HRM Systems into Work Engagement: The Mediating Role of Job Crafting. The International Journal of Human Resource Management, 5192, 0. https://doi.org/10.1080/09585192.2018.1475402 
Organ, D. W. (1988). A Restatement of the Satisfaction Performance Hypothesis. Journal of Management, 14(4), 547-557 https://doi.org/10.1177/014920638801400405

Parasuraman, A., Zeithaml, V. A., \& Berry, L. L. (1996). Conceptual Framework and Hypotheses Development. Contributions to Management Science, 60(2), 41-52. https://doi.org/10.1007/978-3-319-10996-1_3

Petrou, P., Demerouti, E., Peeters, M. C. W., Schaufeli, W. B., \& Hetland, J. (2012). Crafting a Job on a Daily Basis: Contextual Correlates and the Link to Work Engagement. Journal of Organizational Behavior , 1120-1141. https://doi.org/10.1002/job

Pranoto, T. (2020). Daya Saing Indonesia 2020. FEB Universitas Indonesia. https://www.feb.ui.ac.id/blog/2020/07/18/lm-feb-ui-umumkan-daya-saing-indonesia-2020/ (diakses pada 3 Desember 2020)

Punjaisri, K., Evanschitzky, H., \& Rudd, J. (2013). Aligning Employee Service Recovery Performance With Brand Values: The Role of Brand-specific Leadership Aligning Employee Service Eecovery Performance with Brand Values: The role of brand-specific. Journal of marketing management, 29(9-10), 981-1006 https://doi.org/10.1080/0267257X.2013.803144

Qiu, S., Alizadeh, A., Dooley, L. M., \& Zhang, R. (2019). Journal of Hospitality and Tourism Management The effects of Authentic Leadership on Trust in Leaders, Organizational Citizenship Behavior, and Service Quality in the Chinese Hospitality Industry. Journal of Hospitality and Tourism Management, 40(June), 77-87. https://doi.org/10.1016/j.jhtm.2019.06.004

Rahimnia, F., \& Sharifirad, M. S. (2015). Authentic Leadership and Employee Well-Being: The Mediating Role of Attachment Insecurity. Journal of Business Ethics, 132(2), 363-377. https://doi.org/10.1007/s10551-014-2318-1

Ryan, R. M., \& Deci, E. L. (2000). Self-Determination Theory and the Facilitation of Intrinsic Motivation, Social Development, and Well-Being. 55(1), 68-78.

Sakuraya, A., Shimazu, A., Eguchi, H., Kamiyama, K., Hara, Y., Namba, K., \& Kawakami, N. (2017). Job Crafting, Work Engagement, and Psychological Distress among Japanese Employees: A cross-sectional study. BioPsychoSocial Medicine, 11(1), 1-7. https://doi.org/10.1186/s13030-017-0091-y

Sanchez, R., \& Heene, A. (1997). Managing for an Uncertain Future. International Studies of Management \& Organization, 27(2), 21-42. https://doi.org/10.1080/00208825.1997.11656706

Schneider, B., White, S. S., \& Paul, M. C. (1998). Linking Service Climate and Customer Perceptions of Service Quality: Test of a Causal Model. Journal of Applied Psychology, 83(2), 150-163.

Stoverink, A. C., Chiaburu, D. S., Li, N., \& Zheng, X. (2018). Supporting Team Citizenship: The Influence of Team Social Resources on Team-Level Affiliation-Oriented and ChallengeOriented Behaviour. Human Resource Management Journal, 28(2), 201-215. https://doi.org/10.1111/1748-8583.12173

Sutrisno, E. (2009). Manajemen Sumber Daya Manusia (1st ed.). Perpustakaan Nasional: Katalog Dalam Terbitan.

Teece, D. J. (2007). Explicating Dynamic Capabilities: The Nature and Microfoundations of (Sustainable) Enterprise Performance. Strategic Management Journal, 28(August), 1319-1350. https://doi.org/10.1002/smj 
Aziz Yogatama \& Dwiarko Nugrohoseno. Pengaruh Authentic Leadership terhadap CustomerOriented Organizational Citizenship Behavior dan Service Recovery Performance melalui Job Crafting dan HR Flexibility

Tims, M., Derks, D., \& Bakker, A. B. (2016). Job Crafting and its Relationships with Person-job Fit and Meaningfulness: A Three-wave Study. Journal of Vocational Behavior, 92, 44-53. https://doi.org/10.1016/j.jvb.2015.11.007

Tri Wijayati, D., Fazlurrahman, H., Kholidi Hadi, H., Rahman, Z., \& Kautsar, A. (2020). Coaching As Determinant of Job Performance: Co-working Support as Mediating Variable. KnE Social Sciences, April. https://doi.org/10.18502/kss.v4i7.6855

Tuan, L. T. (2016). How HR flexibility Contributes to Customer Value Co-Creation Behavior. Marketing Intelligence and Planning, 34(5), 646-670. https://doi.org/10.1108/MIP-09-20150186

Van Vaerenbergh, Y., \& Orsingher, C. (2016). Service recovery: An Integrative Framework and Research Agenda. Academy of Management Perspectives, 30(3), 328-346. https://doi.org/10.5465/amp.2014.0143

Walumbwa, F., Avolio, B., Gardner, W., Peterson, S., \& Wernsing, T. S. (2008). DigitalCommons @ University of Nebraska - Lincoln Authentic Leadership: Development and Validation of a Theory- Based Measure. Journal of Management, 34(1), 89-126. https://doi.org/10.1177/0149206307308913

Wang, H. U. I., Sui, Y., Luthans, F., Wang, D., \& Wu, Y. (2014). Impact of authentic leadership on performance: Role of followers 'positive psychological capital and relational processes. Journal of Organizational Behavior, 35, 5-21. https://doi.org/10.1002/job.1850

Way, S. A., Tracey, J. B., Fay, C. H., Wright, P. M., Snell, S. A., Chang, S., \& Gong, Y. (2015). Validation of a multidimensional HR flexibility measure. Journal of Management, 41(4), 1098-1131. https://doi.org/10.1177/0149206312463940

Way, S. A., Wright, P. M., Tracey, J. B., \& Isnard, J. F. (2018). HR flexibility: Precursors and the Contingent Impact on Firm Financial Performance. Human Resource Management, 57(2), 567582. https://doi.org/10.1002/hrm.21867

Wernerfelt, B. (1984). The re-source-based view of the firm. Strategic Management Journal, 5(1), 171-180. https://doi.org/10.1177/1056492611436225

Widhiarso, W. (2010). Membuat Kategori Skor Hasil Pengukuran dari Skala. Yogyakarta Universitas Gadjah Mada.

Williams, L. J., \& Anderson, S. E. (1991). Job Statisfiction and Organizational Commitment as Predictor of Organizational Citizenship and In-Role Behaviors. In Journal of Management (Vol. 17, Issue 3, pp. 601-617).

Wong, A., Liu, Y., \& Tjosvold, D. (2015). Service Leadership for Adaptive Selling and Effective Customer Service Teams. Industrial Marketing Management, 46, 122-131. https://doi.org/10.1016/j.indmarman.2015.01.012

Wright, P. M., \& Snell, S. A. (1998). For Toward an Unifying Framework in Fit and Flexibility Exploring Strategic Human Resource Management. 23(4), 756-772.

Wrzesniewski, A., \& Dutton, J. E. (2001). Crafting a Job: Revisioning Employees as Active Crafters of their Work. Academy of Management Review, 26(2), 179-201. https://doi.org/10.5465/AMR.2001.4378011 
Wu, L.-Z., Tse, E. C.-Y., Fu, P., Kwan, H. K., \& Liu, J. (2013). The Impact of Servant Leadership on Hotel Employees' "Servant Behavior." Cornell Hospitality Quarterly, 54(4), 383395. https://doi.org/10.1177/1938965513482519

Xerri, M. J., \& Brunetto, Y. (2013). Fostering Innovative Behaviour: The Importance of Employee Commitment and Organisational Citizenship Behaviour. International Journal of Human Resource Management, 24(16), 3163-3177. https://doi.org/10.1080/09585192.2013.775033

Zhu, X., \& Zolkiewski, J. (2015). Exploring Service Failure in a Business-to-business Context. Journal of Services Marketing, 29(5), 367-379. https://doi.org/10.1108/JSM-02-2014-0055 